\title{
Polyoxymethylene (POM) integrity resulting from its dependencies on material geometries and processing methodology
}

\author{
N. Arifin ${ }^{1,}{ }^{*}$, H. Yusoff ${ }^{2}$, S. Izman ${ }^{2}$, A. Z. A. Khadir ${ }^{2}$, R. Ali ${ }^{1}$, S. Yacob ${ }^{1}$ \\ ${ }^{1}$ Quality Engineering Department, Universiti Kuala Lumpur (UniKL), Malaysian Institute of Industrial Technology, Persiaran \\ Sinaran Ilmu, Bandar Seri Alam, 81750, Johor, Malaysia \\ ${ }^{2}$ Department of Mechanical Engineering, Universiti Teknology Malaysia, UTM Skudai, 81310 Johor, Malaysia
}

\section{A R T I C LE IN F O}

\section{Article history:}

Received 6 November 2016

Received in revised form

4 January 2017

Accepted 7 January 2017

Keywords:

POM materials

Thermo-mechanical

Plastic degradation

Gear geometries

Injection plastic gear

\begin{abstract}
A B S T R A C T
POM-copolymer bond breaking leads to change depending with respect to processing methodology and material geometries. This paper present the oversights effect on the material integrity due to different geometries and processing methodology. Thermo-analytical methods with reference were used to examine the degradation of thermomechanical while Thermogravimetric Analysis (TGA) was used to judge the thermal stability of sample from its major decomposition temperature. Differential Scanning Calorimetry (DSC) investigation performed to identify the thermal behaviour and thermal properties of materials. The result shown that plastic gear geometries with injection molding at higher tonnage machine more stable thermally rather than resin geometries. Injection plastic gear geometries at low tonnage machine faced major decomposition temperatures at $313.61^{\circ} \mathrm{C}$, $305.76{ }^{\circ} \mathrm{C}$ and $307.91{ }^{\circ} \mathrm{C}$ while higher tonnage processing method are fully decomposed at $890^{\circ} \mathrm{C}$, significantly higher compared to low tonnage condition and resin geometries specimen at $398^{\circ} \mathrm{C}$. Chemical composition of plastic gear geometries with injection molding at higher and lower tonnage are compare based on their moisture and VOC content, polymeric material content and the absence of filler. Results of higher moisture and VOC content are report in resin geometries $(0.120 \%)$ compared to higher tonnage of injection plastic gear geometries which is $1.264 \%$. The higher tonnage of injection plastic gear geometry are less sensitive to thermo-mechanical degradation due to polymer chain length and molecular weight of material properties such as tensile strength, flexural strength, fatigue strength and creep resistance.
\end{abstract}

(C) 2017 The Authors. Published by IASE. This is an open access article under the CC BY-NC-ND license (http://creativecommons.org/licenses/by-nc-nd/4.0/).

\section{Introduction}

The use of POM is growing steadily in the automotive and electronic industries. Ever since the unique physical and chemical properties and the ease of production allow the special of materials to start thriving in the global market from household items to biomedical, civil, electronics and automobile sectors. However, a large number of reactions take place during processing and small changes in the molecular structure result in considerable modification of properties of POM material.

\footnotetext{
* Corresponding Author.

Email Address: nurulhuda@unikl.edu.my (N. Arifin)

https://doi.org/10.21833/ijaas.2017.03.007

2313-626X/@ 2017 The Authors. Published by IASE.

This is an open access article under the CC BY-NC-ND license

(http://creativecommons.org/licenses/by-nc-nd/4.0/)
}

In real application of development stage, prototyping is important to investigate and validate a new design to enhance confident level before shifting to mass production. These include plastic gear that are now frequently utilize at present industry. However, the potential deficiencies across dissimilar process and its effect on the integrity of the plastic material may rise due to this different.

These profounder issues are not often given proper consideration until a related gear failure demands study and evaluation. With molded plastic gears, this practice of relying on physical measurements as proof of quality overlooks potential deficiencies in the injection molding process and the effect of material geometries on the integrity of the plastic material. Thus, the aim of the present study is to present changes the molding deficiencies and to discuss the hidden effects produced at the end properties of plastic gear. There is a lot of published data available on the physical 
properties only. Unfortunately, not much information about on how POM material's properties are affected material geometries and processing conditions during injection molding.

For POM material, a good approach for the quantification of degradation induced under service lifetime is to determine stabiliser consumption and beginning degradation by means of TGA. Basically, the decrease of the onset temperature in the thermogravimetric Analysis (TGA) is the first indication for thermo-oxidative damage, whereas a decrease of the onset temperature without a change of the first derivative of the TG signal (DTG) refers explicitly to stabiliser consumption. Degradation can be determined by a change of the DTG signal (Archodoulaki et al., 2007)

\section{Experiment design}

Three samples of POM (polyoxylmethylene) material are prepared for resin, POM gear with higher tonnage and lower tonnage under injection moulding processing method. Thermogravimetric (TG) studies were carried out with a TGA 2050. The sample for higher and lower tonnage of plastic gear injection condition were cut into small pieces, conditioned at room temperature with $50 \%$ Humidity for $3 \mathrm{~h}$ before it were heated from $30^{\circ} \mathrm{C}$ to $1000^{\circ} \mathrm{C}$ at $20^{\circ} \mathrm{C} / \mathrm{min}$ with $\mathrm{N} 2$ gas purging. For the condition of Differential Scanning Calorimetry (DSC), the investigation was carried out by cut off the samples of higher and lower tonnage condition into small pieces before it was heated with $\mathrm{N}_{2}$ gas purging based on the heat cycle which are; heat from $30^{\circ} \mathrm{C}$ to $250^{\circ} \mathrm{C}$ at $10^{\circ} \mathrm{C} / \mathrm{min}$, isothermal at $250^{\circ} \mathrm{C}$ for 1 minute, cool from $250^{\circ} \mathrm{C}$ to $30^{\circ} \mathrm{C}$ at $10^{\circ} \mathrm{C} / \mathrm{min}$, isothermal at $30^{\circ} \mathrm{C}$ for 5 minute and heat from $30^{\circ} \mathrm{C}$ to $250^{\circ} \mathrm{C}$ at $10^{\circ} \mathrm{C} / \mathrm{min}$ (Figs. $1-3$ ).

\section{Results}

Table 1: The composition and major decomposition temperature of resin, sample of gear for higher tonnage and gear with lower tonnage processing method

\begin{tabular}{cccc}
\hline \multirow{2}{*}{ Samples ID } & \multicolumn{3}{c}{ Composition (Weight \%) } \\
\cline { 2 - 4 } & Major & Moisture and VOC & Polymeric Materials \\
& Decomposition Temperature $\left({ }^{\circ} \mathrm{C}\right.$ ) & $30-242^{\circ} \mathrm{C}$ & $243-397^{\circ} \mathrm{C}$ \\
\hline Resin & 305.76 & 0.12 & 99.856 \\
Gear 1 (Higher tonnage) & 313.61 & 1.264 & 98.281 \\
Gear 2 (Lower tonnage) & 307.91 & 1.199 & 98.696 \\
\hline
\end{tabular}

The chemical composition of gear with both higher and lower tonnage injection process are comparable based on their moisture and VOC content, polymeric material content and the absence of filler. The result showing that the chemical composition of pure resin and gear (higher tonnage injection) are comparable except for significantly higher moisture and VOC content in pure resin $(0.120 \%)$ as compared to $1.264 \%$ for sample of gear that undergoes the process of higher tonnage injection molding condition.

Different machine setting were examined in order to confirm the effect of the processing conditions and to discover to what extent

\subsection{Thermogravimetric analysis (TGA)}

The thermal stability of sample was judged from its major decomposition temperature. By referring to the Table 1, testing samples of gear with higher tonnage processing method is slightly more stable thermally compare than pure resin and gear with lower tonnage samples where their respective major decomposition temperatures are $313.61^{\circ} \mathrm{C}, 305.76^{\circ} \mathrm{C}$ and $307.91^{\circ} \mathrm{C}$ respectively. The temperature at which Gear 1 fully decomposed is $890^{\circ} \mathrm{C}$, significantly higher than those of Gear 2 and pure resin of $\mathrm{POM}$ which is at $398^{\circ} \mathrm{C}$.

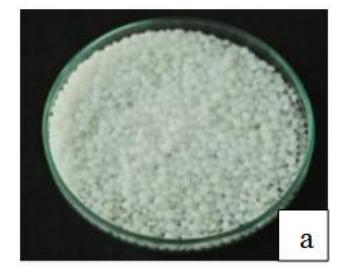

Fig. 1: POM resin

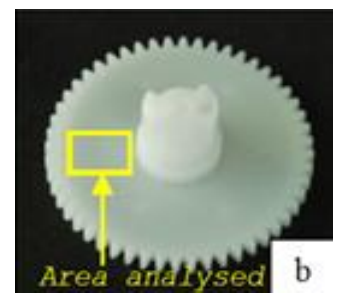

Fig. 2: Sample gear 1(high tonnage injection)

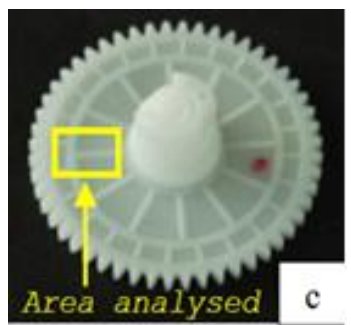

Fig. 3: sample sear 2 (low tonnage injection) degradation takes place during processing. Additionally, different injection moulding geometries and their influence on the degradation behaviour were compared. Figs. 4-6 compare the results of the Resin (mixing), sample Gear 1 and Gear 2 each after variation of the processing conditions. It can be shown that POM copolymer in Figs. 4-6 show onset line indicating some chains that are affected due to the higher temperature (Luftl et al., 2006). Application of the different processing methodology, for example increasing the injection moulding tonnage shows a decreased onset temperature corresponding to a degradation of POM. It is also reveal from the TGA investigations in nitrogen 
atmosphere with $50 \%$ humidity for 3 hours at room temperature, reveal that there is an influence of the used mould geometry on the degradation behaviour of POM copolymer (Figs. 4 and 5). On the other hand, the thermal stability reduce for all investigated materials extracted from structural components either pellets or specimens due to the processing methodology.

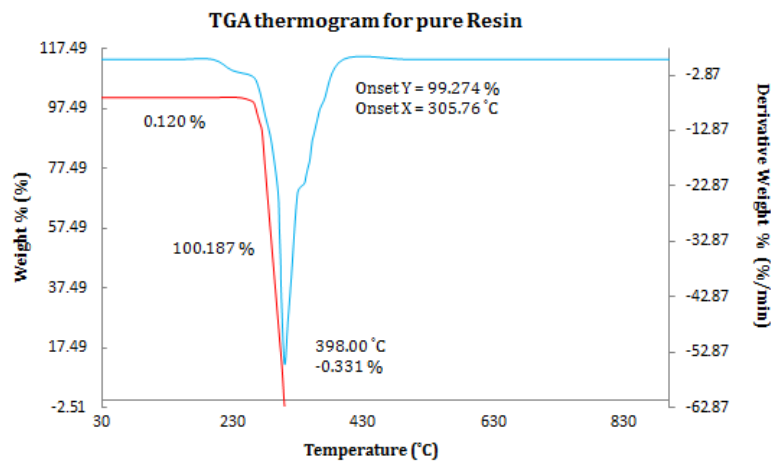

Fig. 4: TGA thermogram for pure Resin POM

Although resin, Gear 1 and Gear 2 are made of comparatively same material base, their thermal stability which is reflected by their onset decomposition temperature is different. The onset temperature of the resin is $305.76^{\circ} \mathrm{C}$, Gear 1 is $313.61^{\circ} \mathrm{C}$ while Gear 2 is at $307.91^{\circ} \mathrm{C}$. For such parts requiring optimum mechanical properties such as gear, it should be mold with high specific hold pressures. For this case, Polyoxymethelene (POM) is equally stiff and a lower flow material, so the injection mold clamp factor used must be towards the high side (Rayand and Ralph, 2012; Wright et al., 1988; Xioa and Zhang, 2002) (Figs. 5 and 6).

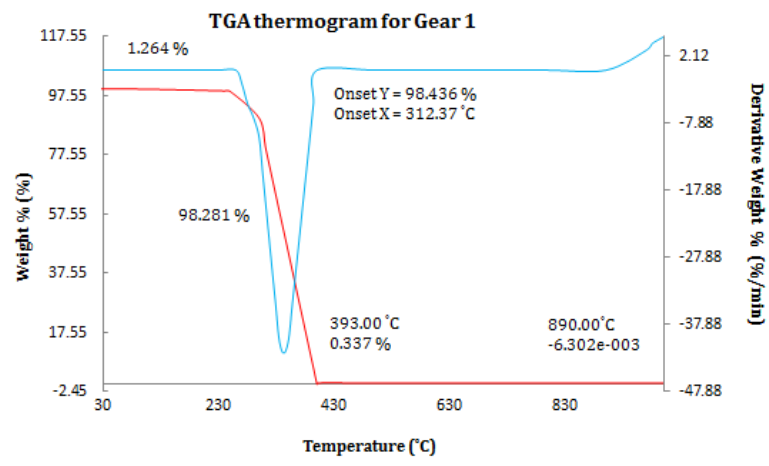

Fig. 5: TGA thermogram for sample of POM gear with higher tonange processing method

\subsection{Differential scanning calorimetry (DSC)}

Table 2 shows the data collection on the composition and major decomposition temperature of resin, sample of gear for higher tonnage and gear with lower tonnage processing method.

The results are obviously shown that there are no significant difference was observed in these samples for peak melting temperature, onset crystallization temperature and peak crystallization temperature. Other than that, there are no significant difference are recorded in peak melting temperature, onset crystallization temperature and peak crystallization temperature was observed between first heat cycle and second heat cycle for the same sample. The material is likely to be the copolymer of POM based on its melting temperature of $168-172^{\circ} \mathrm{C}$ (Figs. 7-10).

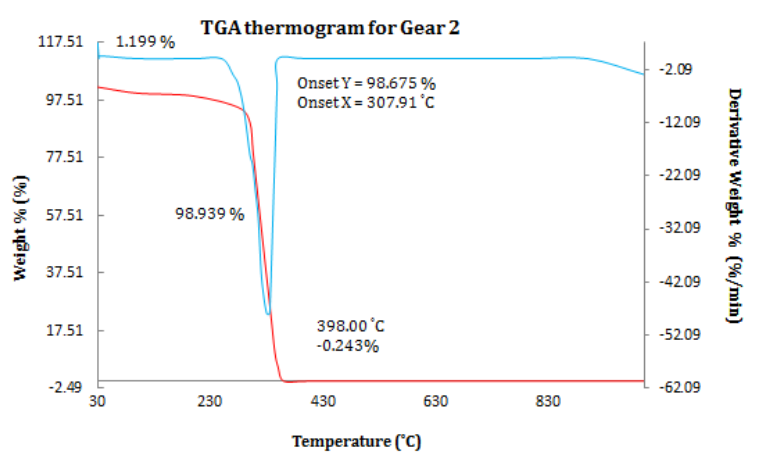

Fig. 6: TGA thermogram for sample of POM gear with lower tonange processing method

\section{Conclusion}

Gear 1 (higher tonnage injection) and Gear 2 (lower tonnage injection) were prepared using POM copolymer material. They have comparable melting temperatures, crystallization temperatures and chemical compositions. However Gear 1 has slightly higher thermal stability than Gear 2 although the difference may not be significant due to the processing injection method condition and its geometries.

\section{Acknowledgment}

We are thankful to our colleagues Mr Hafizzal from Universiti Teknologi Malaysia (UTM) who is doing well the collaboration in providing an expertise that greatly assisted the research and moderated this paper in line improved the manuscript significantly. We also express an appreciation to Universiti Kuala Lumpur, Malaysia by supporting the funding of project under short term grant (STRG 14032).

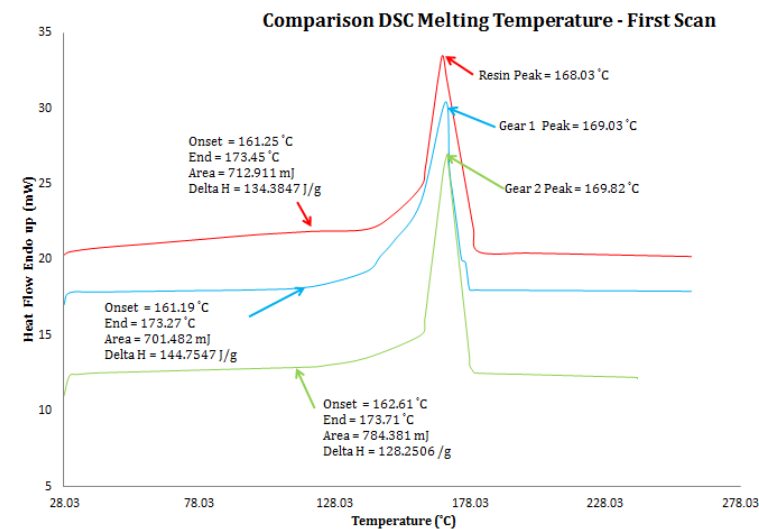

Fig. 7: Comparison DSC Thermogram for melting temperature between resin, sample Gear 1 (higher tonnage injection mould) and Gear 2 (lower tonnage injection mould)-First Scan 


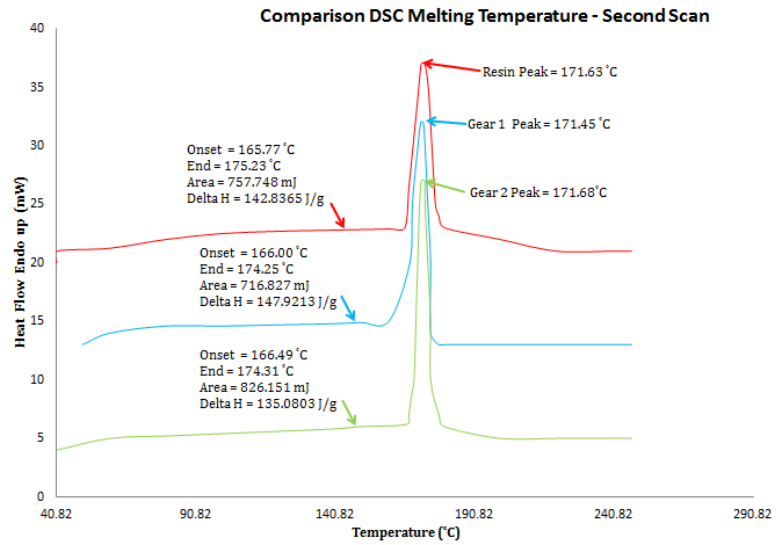

Fig. 8: Comparison DSC Thermogram for melting temperature between resin, sample Gear 1 (higher tonnage injection mould) and Gear 2 (lower tonnage injection mould)-Second Scan

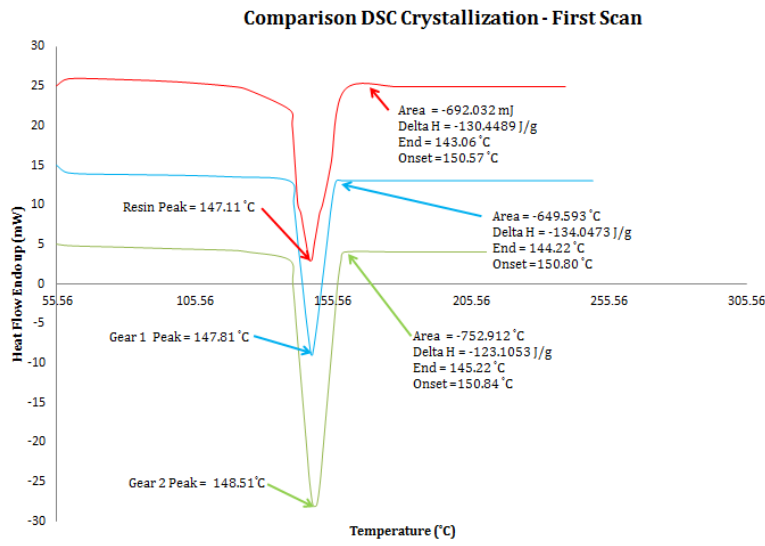

Fig. 9: Comparison DSC Thermogram for Crystallization between resin, sample Gear 1 (higher tonnage injection mould) and Gear 2 (lower tonnage injection mould)-First Scan

Table 2: The composition and major decomposition temperature of resin, sample of gear for higher tonnage and gear with lower tonnage processing method

\begin{tabular}{|c|c|c|c|c|}
\hline \multirow{2}{*}{ Heat Cycle } & \multirow{2}{*}{ Samples ID } & \multirow{2}{*}{ Melting Temperature $\left({ }^{\circ} \mathrm{C}\right)$} & \multicolumn{2}{|c|}{ Crystallization Temperature $\left({ }^{\circ} \mathrm{C}\right)$} \\
\hline & & & Peak & Onset \\
\hline \multirow{2}{*}{ First } & Resin & 168.03 & 147.11 & 150.57 \\
\hline & Gear 1 (HT) & 169.03 & 147.81 & 150.80 \\
\hline \multirow[b]{2}{*}{ Second } & Resin & 171.63 & 147.29 & 150.61 \\
\hline & Gear 1 (HT) & 171.45 & 147.44 & 151.07 \\
\hline
\end{tabular}

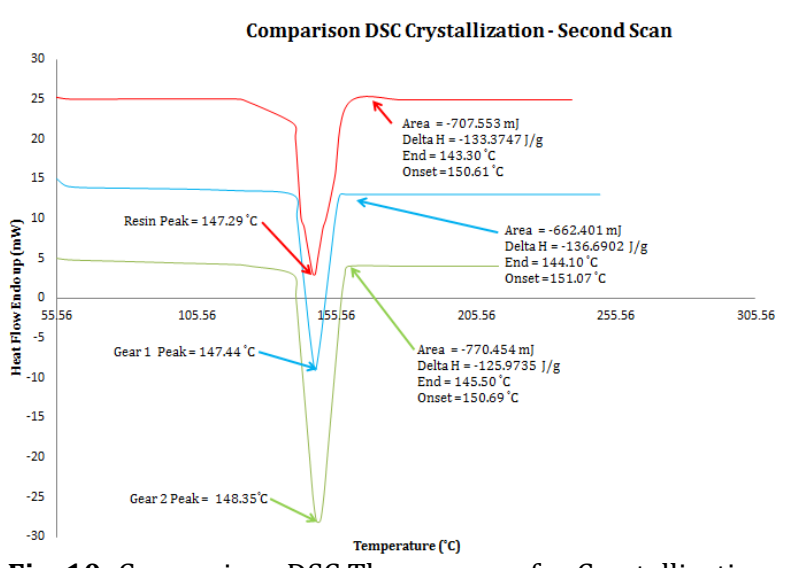

Fig. 10: Comparison DSC Thermogram for Crystallization between resin, sample Gear 1 (higher tonnage injection mould) and Gear 2 (lower tonnage injection mould)Second Scan

\section{References}

Archodoulaki VM, Luftl S, Koch T, and Seidler S (2007). Property changes in polyoxymethylene (POM) resulting from processing, ageing and recycling. Polymer Degradation and Stability, 92(12): 2181-2189.

Luftl S, Archodoulaki VM, and Seidler S (2006). Thermal-oxidative induced degradation behaviour of polyoxymethylene (POM) copolymer detected by TGA/MS. Polymer Degradation and Stability, 91(3): 464-471.

Rayand S and Ralph PC (2012). Thermal degradation of polymer and polymer composites. In: Kutz M (Eds.), Handbook of Environmental Degradation of Materials: 213-238. $2^{\text {nd }}$ Edition, Elsevier, Amsterdam, Netherlands.

Wright DG, Dunk R, Bouvart D, and Autran M (1988). The effect of crystallinity on the properties of injection moulded polypropylene and polyacetal. Polymer, 29(5): 793-796.

Xioa KQ and Zhang LC (2002). The role of viscous deformation in the machining of polymers. International Journal of Mechanical Sciences, 44(11): 2317-2336. 